\title{
The origins and meaning of the Schaechter-Maaløe-Kjeldgaard experiments
}

\author{
STEPHEN COOPER* \\ Department of Microbiology and Immunology, University of Michigan Medical School, Ann Arbor, \\ MI 48109-0620, USA
}

\section{Introduction}

In 1958, the Journal of General Microbiology published two papers that were to give birth to a new field of microbiology. Not only have these papers by Moselio Schaechter, Ole Maaløe and Neils Ole Kjeldgaard inspired many discoveries and defined a new area of research, but they have had an enduring importance that qualifies them for inclusion in the canon of great microbiological literature (Schaechter, Maaløe \& Kjeldgaard, 1958; Kjeldgaard, Maaløe \& Schaechter, 1958). Unfortunately, these papers are not well known. In this article, I take a new look at the history of these papers, describing why the experiments were done and how they were viewed in their time.

\section{The experiments}

The experiments were simple in concept. The first paper, with the modest title 'Dependency on medium and temperature of cell size and chemical composition during balanced growth of Salmonella typhimurium', described the chemical composition of Salmonella typhimurium growing in a number of different media. Schaechter, Maaløe and Kjeldgaard determined the composition of cells growing over a wide range of growth rates, from 20 to 150 min doubling times. They observed that the faster the growth rate, the more RNA, DNA, protein and nuclei were found in each cell - that is, faster growing cells were larger and slower growing cells were smaller. Furthermore, they concluded that cell size was independent of the medium used to obtain a particular growth rate - at a given temperature, for a given growth rate, no matter how the medium was altered, the average composition of the cell was set by the growth rate. Schaechter, Maaløe and Kjeldgaard's precise measurements allowed them to conclude that the steady-state cell size increased exponentially when plotted against the

\footnotetext{
*Tel. (313) 764 4215; fax (313) 764 3562; e-mail USERLC4J (a) UMICHUM.BITNET.
}

reciprocal of the doubling time. The second paper, 'The transition between different physiological states during balanced growth of Salmonella typhimurium', described experiments in which cells at one growth rate were shifted to a different growth rate. Cells growing in a slow-growth medium (producing smaller cells) and shifted to a fast-growth medium (producing larger cells) undergo a shift-up. This paper described how cells grew, divided and changed during the shift-up transition.

I have been thinking about these experiments for almost 30 years, and recently entitled them the 'Fundamental experiments of bacterial physiology' (Cooper, 1991). I thought I fully understood their origins and meaning; now I have discovered more. The first paper appeared to have its origin in the analysis of continuous, steady-state growth; it does not. The second paper appeared to follow with a logical analysis of the changes during the change in medium; it does not.

\section{The bacterial life cycle}

The Schaechter-Maaløe-Kjeldgaard papers present a flow of ideas from the initial demonstration that there is no obligatory life cycle, to the final explanation of the way cell sizes are determined by different growth rates. Schaechter, Maaløe and Kjeldgaard grew bacteria in different media at low cell densities with good aeration by repeatedly diluting the cultures; the cells grew indefinitely in the exponential phase. This is steadystate, balanced, exponential growth, with all components of the culture increasing continuously and in parallel. This equal and constant rate of increase means that cell size is constant at each growth rate. Cells grew fastest in Brain Heart infusion; these fast growing cells were almost six times larger than the slowest growing cells in lysine minimal medium.

The idea of the bacterial life cycle was developed during the first two decades of this century, culminating in the description by Buchanan (1918) of different phases of the bacterial life cycle. This formulation was most complex, with lag, acceleration, early-, mid- and late-log, deceleration, stationary and death phases. The bacterial 
life cycle was thought to be a necessary progression through which cells must pass between inoculation from an overgrown culture to the final production of a new overgrown culture. Cultures were given anthropomorphic properties, at first young and robust, then old and frail. (Today, Buchanan's description of the bacterial life cycle is part of every microbiology text without mention of its author. Though it is a sophisticated and influential paper, it is essentially unread and unknown.)

The life cycle view was subsequently popularized by Henrici (1928) in a monograph entitled 'The life cycle of bacteria'. Henrici looked at bacteria in different growth phases and observed that cells in an overgrown culture were small. The cells enlarged during the lag phase and were largest during exponential growth. As cell growth decelerated, the cells got smaller and returned to their smallest size at stationary phase. This variation in cell size was, according to Henrici, the morphological and cellular correlate of the classic life cycle of the bacterial culture.

Thirty years later, Schaechter, Maaløe and Kjeldgaard demonstrated that there was no obligatory life cycle. In contrast to the life-cycle model, variation in cell size during culture growth was due simply to varying growth rates. Non-growing, stationary phase cells were small and had the lowest possible growth rate. Cells diluted into fresh growth medium grew larger, and obtained their largest size at the fastest growth rate. In the second paper, Kjeldgaard, Maaløe and Schaechter confirmed this analysis by describing how cells achieved a new steady-state cell size following a shift from a poor medium to a rich medium. It is an a priori necessity, given the steady-state size variation with growth rate, that during a shift-up from one steady state to another, mass must increase faster, or earlier, or in some way more, than cell number. This is the only way for cells to get bigger. They unexpectedly found that cell size changed in a precise methodical manner. Following a shift-up, the rate of increase in cell number continued at the old rate for $60 \mathrm{~min}$, while cell mass growth changed to the new rate almost immediately. The change in cell size during this $60 \mathrm{~min}$ transition period allowed the cells to reach a size appropriate to the new steady state. At 60 min after the shift, the rate of cell division abruptly changed to that of the new growth rate. These two papers together give a complete picture of steady-state growth and the transition between steady states. The old lifecycle concept was eliminated; bacterial growth was now based on defined, reproducible and balanced growth conditions.

In fact, the history is not so clear. In the late 1940s, Monod included the idea of steady-state growth in his work. Fred Neidhardt remembers that in 1952, when he was a graduate student at Harvard, he was 'taught' that steady-state growth was the only way to study bacterial physiology. And in 1957, Allan Campbell defined 'balanced growth' as the condition of steady-state growth with all components increasing at the same rate. The ideas of steady-state growth were in the air long before the two Schaechter-Maaløe-Kjeldgaard papers were published.

It now appears that Schaechter, Maaløe and Kjeldgaard's purpose was to define the different steady states in terms of cell composition and cell size. Re-reading the papers, I can imagine the three of them rationally discussing, over Danish pastry, the bacterial life-cycle, thinking about reconciling the bacterial cell-size changes during the life-cycle with steady-state growth, and coming up with a series of experiments to determine cell sizes at different growth rates. This, however, was not the genesis of the experiments. It is now the conventional wisdom that scientific papers are not historical records, and that the untidy act of discovery is lost in the writing of the paper. In the case of the Schaechter-MaaløeKjeldgaard papers, the actual experimental progression is not only obscured but reversed. The history is also important because it contains important lessons regarding the nature of scientific discovery. To understand how these discoveries were made, we must look into the history of each of the participants.

\section{The participants}

\section{Ole Maaløe}

Maaløe passed his examination in medicine from Copenhagen University in 1939 , and spent a couple of years in various paediatric hospital departments. There Ole did some research on immune resistance in infants. This work led him to establish contact with Jeppe Ørskov, then director of the State Serum Institute, who suggested that Ole should join the Institute. Ole started in 1942 at the serodiagnostic department, first as an unpaid volunteer, later as a research assistant. His immunological work led to his 1946 doctorate thesis ' On the relation between alexin and opsonin'. As harbinger of things to come, this work involved studies of bacterial killing by complement in serum using careful bacterial plate counts. As we shall see, careful plate counts, as mundane as they may appear, were part of the key to Ole's future success.

In 1948, Ole was appointed head of the Standardization Department of the Serum Institute. The department was affiliated with the World Health Organization as a centre for a number of standard antisera. As the official duties did not require much more than 1 day a week, and as these were mostly undertaken by Maaløe's long-time major-domo Ole Rostock (who followed him to his later position as director of the University Institute 
of Microbiology), Maaløe developed his situation into an excellent research department.

In 1949, Ole got a 4 month Rockefeller Travel Grant to visit various bacteriological laboratories in the USA. Herman Kalckar recommended to Ole that he visit C. B. van Niel in Pacific Grove and Max Delbruck at the California Institute of Technology. During the Second World War, Kalckar was stranded in the USA where he worked with Fritz Lipmann and Carl Cori and became acquainted with everybody in American biochemistry. It appears fortunate that Kalckar sent Ole to two bacteriologists, rather than biochemists, as this led to work in a field in which Ole was to excel. Although the concept has not been deeply explored, it can be speculated that people who work in scientific fields that suit their personality are more likely to succeed than if mismatched. Although one has only hindsight as a guide, Ole would probably not have liked the type of work involved in biochemistry. He was much more comfortable with mentally understanding complex systems rather than physically taking them apart. As we shall see, Ole flourished with a problem that required deep thought, rather than complex experimental work.

The crucial and fortunate visit of Maaløe was to the laboratory of Max Delbruck. Delbruck was famous for his clarification of the nature of bacteriophage and bacteriophage growth kinetics. The central experiment of bacteriophagy was the single-step growth curve. Rather than having an asynchronous and ill-defined pattern of growth, Delbruck devised conditions for simultaneous infection of bacteria, elimination of secondary infection by released bacteriophage, and reliable quantification of the released bacteriophage. The history of this phase of molecular biology has been written many times. All that needs to be pointed out here is that the single-step growth curve was an important milestone, it made Max Delbruck famous in biology, and in retrospect opened up much of the field that we now recognize as molecular biology. (The original papers were written by Ellis and Delbruck; sadly, Ellis had to leave the phage field at this exciting time because his funding was for 'cancer research' and it did not appear that this phage work was as important as the direct attack, in 1939, of the cancer problem; so much for basic research.)

Maaløe was welcomed into the phage group. As a member of the early 'phage group,' Ole actually began to work on phage. He did some work on phage with Jim Watson when Watson left the Kalckar laboratory before moving on to Cambridge. But in retrospect, besides some very respectable work, nothing major came out of the laboratory. Ole was close to experiments that might have antedated the Hershey-Chase experiment, but once the DNA story came out, the path on which he was working may have been foreclosed.
In 1951-1952, Ole worked in Delbruck's laboratory. When he returned to Copenhagen he was joined by two postdoctoral fellows, Vic Bruce (Delbruck's brother-inlaw) and Gordon Lark. A few years later, Elio Schaechter and Neils Ole Kjeldgaard joined the laboratory. In 1948, Neils Jerne got a position in the Standardisation Department. Considering that Jim Watson also joined Ole's laboratory in 1950, it must have been an exciting place with two future Nobel Laureates in daily attendance.

Gordon Lark was a student of Mark Adams, one of the early workers on bacteriophage. Lark received his $\mathrm{PhD}$ from New York University, and it was during a visit by Ole to the laboratory of Pappenheimer that Ole met Lark. He invited Lark to spend a postdoctoral visit in Copenhagen. Lark heard that Stent and Watson were enjoying themselves in Copenhagen, and this was a good enough recommendation. The initial conversations discussed further work on T4 phage and related problems, but the direction of work changed completely when Lark arrived in Copenhagen.

When Lark arrived the T4 project was shelved, and he began work on the synchronization of bacteria. A number of threads of influence led to the synchrony work. The results of Howard and Pelc on the different phases of the eukaryotic division cycle (1951-1953) had just made a large impact, and it was important to know if similar phases were present in bacteria. At this time, there was no clear and accepted distinction between bacteria and higher cells. One could, in theory, expect to find that bacteria were similar to onion root tips. But probably the strongest influence on this direction of the initial work in Copenhagen was Lark's knowledge of the work of Rollin Hotchkiss, at the Rockefeller Institute, on the synchronization of bacteria. Hotchkiss used temperature shifts to synchronize bacteria, specifically to find out whether there was some cell-cycle specificity for the transformation of Pneumococcus by DNA. Hotchkiss did get peaks of transformability, and this was attributed to cell changes during the division cycle. The scientific circle in New York City was sufficiently small that Lark knew of the work and understood its importance even before publication. He brought this knowledge with him to Copenhagen. Soon Lark and Ole were using temperature shifts to synchronize Salmonella. When the DNA content was measured in the heatshocked synchronized cultures, Lark observed a period of DNA synthesis in the middle of the division cycle. So here the story appears complete. Bacteria are like animal cells; they have G1, S and G2 phases, presumably a mitotic phase, and there is a complex and interesting life cycle to be studied.

But a cautionary tale enters. Later Maaløe, along with Schaechter and Bentzon, demonstrated that the synchro- 
nization results were due to an artifact. One of the first experiments that Schaechter tried upon arriving in Copenhagen was to prove the Lark results by a simpler experiment than synchronization. If DNA was synthesized during a fraction of the division cycle, then a pulselabel specific for DNA should label only a fraction of the cells in the culture. Initial work with ${ }^{32} \mathrm{P}$ was a disaster, as not only were cells filled with RNA, but the presence of phospholipids also obscured any DNA-specific labelling. Eventually, tritiated thymidine became available commercially, and in one of its first uses to label bacteria (it may have been that Fred Forro was using it earlier), Schaechter and Maaløe demonstrated that a short pulse with radioactive thymidine labelled all cells in a culture. Thus, there was no short 'S-phase' in bacteria. If there were any 'gaps' in DNA synthesis, one would expect some unlabelled cells. DNA synthesis, in an unperturbed, normal growth situation, was actually continuous during the division cycle.

\section{Neils Ole Kjeldgaard}

The other Dane in the experimental trio was Kjeldgaard. $\mathrm{He}$ is thoroughly Danish, but cosmopolitan in training. $\mathrm{He}$ enrolled in Copenhagen University in 1945 as a student of biochemistry. He joined Kalckar's laboratory in 1948 to study the inhibition of xanthine oxidase by pteridylaldehyde. This was just a prelude to his next position at the Institut Pasteur to which he went in 1949. He had a French Government Fellowship to study with Andre Lwoff, as was suggested by Kalckar. This was Kjeldgaard's first introduction to bacteriology and how to grow bacteria. Along with Louis Siminovitch he joined in the chase for the induction of a lysogenic strain of Bacillus megaterium. Although lysis of random individual cells had been observed, no systematic, total induction of the culture was available. So along with Sarah Rapkine and Siminovitch, Kjeldgaard grew the bacteria in a multitude of different media (a premonition of work to come?), varying the energy source, changing the redox potential of the medium, limiting the oxygen supply, changing the $\mathrm{pH}$, using overgrown media, and all of the other things they could think of. One day UV was on the agenda, and as we now know, lysis ensued.

Surprisingly, Kjeldgaard did not stay on at the Institut Pasteur despite an invitation from Lwoff to do a French $\mathrm{PhD}$ thesis. Kjeldgaard wanted to go back to Denmark for his degree. But in 1950 Copenhagen was a disappointment, as there was no-one interested in lysogeny and lysis induction.

Kjeldgaard did receive his degree in 1951 and he then obtained a Carlsberg fellowship to work with Erik Zeuthen on the synchronization of cell division in
Tetrahymena. Zeuthen had taken a post at the Institute of Zoophysiology, and became interested in studying cell division. Along with Heinz Holter, Zeuthen used the principle of the Cartesian diver, which enabled one to measure the weight of single cells. The idea was to eventually measure the growth of single cells during the division cycle. Kjeldgaard embarked on attempts to synchronize Tetrahymena by starvation, but without much success. It is interesting that the work with Tetrahymena may have started Kjeldgaard thinking of the growth of cells during the division cycle; another precursor to the later work thus appears.

Two years later a fateful meeting took place. As Kjeldgaard modestly describes it, in 1956 Jacques Monod gave a major talk in Copenhagen. At the dinner after the talk, where Maaløe and Gordon Lark were present, Monod suggested that Kjeldgaard should return to academic research. Shortly after that dinner Maaløe called and offered Kjeldgaard a fellowship to work at the State Serum Institute. As Lark tells it, the story is more exciting. As the famous Monod was about to start his lecture he noticed Kjeldgaard in the audience; he walked down from the dais, went over to Kjeldgaard - who Monod knew from his earlier work with Lwoff - and greeted him with joy and enthusiasm. This recognition of Kjeldgaard by Monod was noted by Maaløe. Soon Maaløe extended an invitation to Kjeldgaard to come work in his laboratory.

When Kjeldgaard started work at the Serum Institute, Gordon Lark had just left and Ole needed someone to continue the synchrony work. The degree of synchrony was not good, and Maaløe set very rigorous standards about what was to be accepted as a good synchrony experiment. He required an exact doubling of cell numbers for each division cycle, and the maintenance of the correct doubling time between subsequent rises in cell number. Ole occupied the same position in bacterial growth studies as Delbruck in phage studies. He could be a judge of when work was good, and this enabled the field to reject work that was not up to par.

As part of the programme to improve synchronization, Kjeldgaard tried to follow up on an initial observation by Vic Bruce that optical density variations could be used to monitor synchrony. After a lot of work this did not succeed; no oscillations were observed. We now know that the exponential growth of bacterial cells during the division cycle would give an exponential increase in cell mass, and thus optical density, even if the cells were well-synchronized.

\section{Moselio Schaechter}

Schaechter, the third member of the team, was born in Italy. He left Europe with his family for Ecuador during 
the Second World War, came to the USA for a Master's degree at the University of Kansas, and eventually received his $\mathrm{PhD}$ from the University of Pennsylvania in the laboratory of Edward DeLamater. DeLamater was well-known for his report of mitosis in bacteria. $\mathrm{He}$ observed and drew pictures of bacterial chromosomes condensing, moving about, and displaying the same chromosomal mechanics as found in eukaryotic systems. We see in this work, as in the study of bacterial phases of the division cycle, a feeling that there would be a unity between bacteria and higher cells with regard to growth and division. The controversy regarding bacterial mitosis, with Carl Robinow in the opposition, finally ended with the conclusion that bacteria may have nuclear bodies, but no mitosis. Schaechter, known to his friends as Elio, worked on the cytology of mitosis in the alga Chlamydomonas, and had the valuable experience of learning to stain chromosomes. As we shall see, this was important for his subsequent work in Copenhagen.

After graduation Elio was drafted into the Army, but he served in Washington at Walter Reed Hospital studying the synthesis of ribosomes in the presence of chloramphenicol. This work had two aspects which relate to the later work. First, his work with the chloramphenicol particles (as the sub-ribosomal particles were called) was to enable him to think in mechanistic terms about protein synthesis; the involvement of RNA and ribosomes was one of the central parts of the later work. Second, and more important, he became adept at the colorimetric assays of RNA with orcinol and DNA with diphenylamine. One gave a green colour, and the other a blue colour, and Elio learned to accurately determine each component in cell extracts. As we shall see, this played on important part in the later Copenhagen experiments.

One other project which Elio worked on at this time was important for the future experiments. There was controversy on the mode of replication of rickettsias. Was there binary fission or something else? Elio looked and saw binary fission. This work allowed Elio to think in terms of the growth of individual cells, and to think about growth of a culture in cellular terms. Thus we see that both Schaechter and Kjeldgaard were already primed to think of the growth of individual cells during the division cycle. When they next meet in Copenhagen, they are prepared to understand bacterial growth in terms of the division cycle.

Army life for Elio was not as barren as one may imagine. Schaechter's unit was loaded with $\mathrm{PhDs}$, and one of them was Allan Campbell. Campbell had read the Lark paper and he mentioned it to Elio and said that this was an important paper. After looking around at various postdoctoral positions, Elio wrote to Ole in Copenhagen, and thus became part of the wave of
Americans who went to Europe after the war for postdoctoral study.

Nowadays, people choose postdoctoral positions in order to learn specific techniques, approaches and experiments that will make them 'employable'. Go to Dr $\mathrm{X}$ because he has a specific sequencing method for doing 40000 bases a week, or has great experience with cloning. But back in the 1950s and 60s the motivation was more amorphous. Techniques were not numerous, and what techniques were being used were not so unique that one had to spend time in a specific laboratory to learn the techniques. Rather than a specific technical motivation, one went to a laboratory in order to absorb the ideas. (That a laboratory was in Europe, and in a beautiful city, with the Tivoli Gardens and smorrebrod, did not make the decision more difficult.)

\section{The experimental process}

Elio arrives in Ole's laboratory. What should he do? As Elio tells it, Ole was still enamoured by the success of the Delbruck's single-step growth curve with phage. After all, this experiment had revolutionized phage work. If great things could be discovered with phage by having a synchronous round of phage synthesis, then equally great things could be found by having a synchronous round of bacterial growth and division. This is the study of the bacterial division cycle, the events between divisions, and the regulation of cell growth and division. Could Ole do with bacteria what had been done with bacteriophage?

The initial work on temperature shifts turned out to be a false start. But undeterred by this result, Ole still felt that synchronization was the right approach to the study of the bacterial division cycle. If heat shocks didn't work, perhaps some other 'shock' would work. Perhaps there was a treatment that would align the bacteria, so they would be synchronized and proceed through the division cycle to allow the events of the division cycle to be studied. When Elio showed up in the laboratory, Ole suggested trying to synchronize cells by utilizing a shift in medium.

As Elio (and others) tell it, there was a particular technique to be learned from Ole Maaløe. Ole had superb skill when it came to enumerating bacteria, and this bacterial counting technique was the key to success. In these days of electronic particle counters, and the ubiquitous presence of electronic as well as manual micropipetters, the approach of Ole to bacterial counting must seem either heroic, quaint or crazy. What Ole had was a large collection of what were known as 'Carlsberg pipettes', so-named because of the Carlsberg Foundation where they were developed and manufactured. Although today these Carlsberg pipettes are more museum pieces 
than anything that would be used in a laboratory, they were wonders at that time. They were thin glass tubes with a constriction. The constriction was marked with a scratch, and each pipette was precisely and individually calibrated and adjusted to hold a particular amount of liquid. Only one volume was carried by any one Carlsberg pipette. This small volume (perhaps $10 \mu \mathrm{l}$ ) was essential for the enzymological work being carried on in the laboratory of Linderstrom-Lang. But as Ole discovered, they were also perfect for bacterial counting.

Ole had worked out a succession of procedures to accurately determine the bacterial concentration. He would approach the shaking flask in the water-bath and take one puff on his cigar. He then placed the cigar on the water-bath, took a sample from the flask and added it to dilution fluid, made a second dilution with another Carlsberg pipette, and then used a third pipette to transfer some of the second dilution to a plate. All of this was accomplished in time for him to reach down at the precise moment necessary to pick up the cigar and take another puff. The alternation of puffing, sampling and plating was the key technique. It allowed quantitative counting over very short periods, even down to a minute or two, with extremely reproducible results.

So the shift of medium experiment proceeds. Cells growing in minimal medium are shifted to broth medium. Ole does the bacterial counting. Elio, with his experience with determinations of DNA and RNA, does the chemical measurements. The initial experiment is a resounding failure in terms of synchrony - no synchronization is observed at all - but a success in terms of understanding bacterial growth. After the shift from minimal medium to broth medium, the bacterial counts do not show any change in the rate of increase. They continue at the pre-shift rate for approximately $60 \mathrm{~min}$ when there is an abrupt change to the new growth rate. The absorbance and chemical measurements show that mass, whether measured in terms of optical density or RNA content, begins to increase almost immediately at the new rate.

Just thinking about this result brings the entire picture together. There must be a different steady-state size after the shift because of the dissociation of cell number increase and cell mass increase. Further, if this experiment is not dependent on the particular two media used, one must imagine that there must be an entire family of different growth rates and growth-rate determined cell sizes. Any of these media must also give a shift-up result with a delay in the increase in cell number - now called 'rate maintenance' - in order to produce the different steady-state growth states. We thus see that the result of the second paper, which appears to develop from the first paper, was actually found first.

The work now takes a different turn. Efforts centre on the accumulation of data on the steady-state compositions of bacteria at different growth rates. Schaechter and Maaløe are joined in this work by Neils Ole Kjeldgaard who runs the Zeiss spectrophotometer - an important instrument in this work, as it was the best spectrophotometer available at that time and enabled them to perform the requisite absorbance measurements. Eventually Elio introduced nuclear staining and counting of nuclei per cell. The three were able to do about four cultures at different growth rates each day. The batch cultures are soon joined by chemostat cultures to study 'slower' growth rates.

The accumulation of data reveals the basic phenomenon. The amount of each component of the cell increases as an exponential of the inverse of the doubling time (i.e. the number of doublings per hour). Their data was good enough to distinguish, even over a relatively limited set of data, between an exponential and a linear function.

While the initial and subsequent shift-up experiments are easy to comprehend, the inverse manipulation, the shift-down experiment, is a more complicated result but equally instructive. One day, Elio thought it would be interesting to try shifting from rich to poor medium, a shift-down. He enlisted Ole Rostock to help him. Rostock would do the plate counts, Elio would do the absorbance measurements. As initially proposed, Elio was going to use centrifugation to wash the rich medium away to allow the cells to be resuspended in a poorer, minimal medium. This technique was abhorrent to Ole, who immediately suspected artifacts even with as gentle a technique as centrifugation. Here luck intervenes. A salesman from Sartorius comes by with the newly developed filtration membranes that are now so ubiquitous; they are offered free so that the laboratory could evaluate them. Elio goes to the shop and has them fabricate a makeshift filter holder large enough to hold a medium-size filter. Elio and Rostock filter the brothgrown cells, wash the cells from the surface and find a complete recovery of absorbance: the cells are not imbedded in the filter but are really on the surface. They begin to watch the growth of the cells resuspended in the minimal medium. Nothing happens; the absorbance does not increase. They continue to take plate counts, but the absorbance is level. They conclude the cells are dead. But they wait. After an hour, a little increase is noted in the absorbance. But this could be the growth of a few live cells coming up in the dead population. Soon growth resumes at the expected rate. The next day, when the cells were counted, it was clear that the cells were not dead. Rather, they were completely viable, and more important, the cell number increased even when the absorbance was constant. This was the inverse of the shift-up. The cells divided and grew similar. The only 
complication was that in the shift-down there is a delay because of the repression of the enzymes during growth in broth. This experiment confirmed, in its own way, all of the shift-up work. Following a shift-down there was a rate-maintenance phenomenon, which was the inverse of the shift-up, but merely complicated by the problem of starvation for a short period of time in the minimal medium.

\section{Solving the cell}

The history of the experiments are obscured by their presentation, since synchronization and the division cycle appear nowhere in the paper. Here we have a case of serendipity in science. While looking for synchronization they actually found no synchronization. They found that there is no change in the order of cell division, for the increase in cell number and cell size is a continuous function. Although the work of Schaechter, Maaløe and Kjeldgaard is not now well known, within it are contained the seeds for understanding the patterns of DNA replication during the bacterial division cycle that were worked out a decade later, the regulation of protein synthesis at different growth rates, and for understanding the growth of the entire cell.

The concept of 'solving the entire cell' has gained prominence in recent years. This idea, of course, applies to determining the complete sequence of the genome of a particular cell. But this is a sterile vision. Even when one knows the entire sequence, what is really meant by 'the cell' is the interaction and relationship and amounts and positions of all of the cell components. When a protein sequence is known it is still important to know its activity in the cell, the number of molecules per cell, and all of the functions of that particular protein within the cell. Such a programme has been dubbed 'reconstructionist' by Michael Savageau (1991). The idea is to reconstruct, if not in actuality at least in concept, the working and functioning of a complete cell in terms of its individual components. This is not a wholistic programme, but rather the ultimate end of all reductionist work applied to understanding cell growth. Without the consistent production of a well-defined and described cell, a cell in balanced growth, growing with a constant cell size and cell composition, it is difficult to know whether such a programme could have been conceivable. If the cell had a definite life cycle, the total solution of the cell would require that it be defined in dynamic terms of the cycle. The solution would include all of the particular sizes and cell compositions at each growth phase. Clearly, such a programme would be more difficult than the one before us today, the complete solution of a cell at a particular growth rate and with a particular metabolic environment.
I previously called the experiments of Schaechter, Maaløe and Kjeldgaard the 'Fundamental experiments of bacterial physiology' (Cooper, 1991). Is this title justified? It is difficult to say. Other experiments could be nominated for such a sobriquet; perhaps Monod's diauxie experiment, or even Buchanan's life-cycle paper, or perhaps Buchner's work on cell-free fermentation, or perhaps any of a number of experiments by Pasteur on the vital functions of bacteria. I have placed the Schaechter-Maaløe-Kjeldgaard experiments at this height because I see within them the link between the reductionist and reconstructionist programmes. It is the initial experiment to which we should return when we wish to understand the growth of the entire cell.

\section{Epilogue}

There are a number of lessons to be learned from this history. One, is that the written paper is no guide to the origins of a particular experiment. Another is that the important results are usually the unanticipated ones. It is the answers to unasked questions that are the most interesting. Finally, papers that are more than 5 years old are still valuable; microbiology is a continuous web of results from the past to the present, and experiments should be compared, when possible, to previous results. We must not forget the past, not because we would otherwise relive it, but because without the past we cannot understand the present and the future.

What was the contribution of Ole Maaløe to all of this? We see him counting cells, and organizing the laboratory and the direction of the research. He is searching for synchronized cells, but the experiments do not work. The shifts of medium do not give synchrony. Here he is flexible and sees that the absence of synchrony is really the beginning of something else. But Ole gave something more intangible to this work, something that is somewhat rare today. As Elio describes it, Ole would come in each morning, around 10 or 11, rather late by today's standards, and look at the previous day's experiment. The plates had been counted, the absorbances measured, and all of the data had been plotted. $\mathrm{He}$ would then retreat into his office to think and think again about it. It was this deep thinking about the experiment and its meaning that gave the work its unusual character. In addition, Schaechter suggests that perhaps the main contribution of Ole was that he saw that the work was important; since it was important, it deserved a lot of thought. In the beginning, Ole didn't know how or why it was significant, but he surely knew it was. This conclusion has been amply confirmed.

Gordon Lark notes that Ole had two characteristics that gave his work its unique quality. First, he was parsimonious in dealing with results. He drained every 
possible result and interpretation from each experiment. He did not throw away data but dealt with it over a long period of time. He thought about results for extended periods, and derived newer insights by just thinking about them. The initial surface result contained deeper results which became apparent only slowly. Also Lark states that Ole had a superb intuition about bacteria. He had internalized a view of bacteria that was for the most part correct but was still quite flexible. He interacted with each piece of data and put it in the context of his current intuitive view of bacteria. This combination of biological intuition and contemplative data analysis may be the true source of his greatness. Another way to phrase this combination is to say that Ole exhibited both Baconian or inductive and Cartesian or deductive approaches to science (Cooper, 1991). He was equally at home with experiment and theory, and he brought to this field a theoretical and analytical approach that was unusual for such a descriptive and experimental science as microbiology.

Word of these experiments spread rapidly. When Elio visited Cambridge soon after the experiments were published, it was obvious that Crick understood the importance of the experiments 'disgustingly early' (Schaechter, 1985). 'Congratulations! You people started a new field, but it will end with what you did.' Luckily, this prophecy did not hold true. Through the years, the experiments have been a touchstone for judging later work. They have served as inspiration for an entire generation who feel themselves part of the 'Copenhagen School'. The ideas and results of the Schaechter-Maaløe-Kjeldgaard experiments have not been exhausted. Rather they must be relearned, restudied and rethought, and applied to the ideas and experimental approaches of today. Therefore, as Arieh Zaritsky has pointed out, perhaps Crick meant something entirely different. It is not that the field ended with these experiments, but that at the end of the field will be when we finally explain the growth of cells in terms of these experiments. It is this interpretation that is well on its way to fulfilment. In this view, the Fundamental Experiment may also be the closing experiment as well as the starting experiment, both the beginning and the ending of a small field of science.

I want to thank Elio Schaechter for his time that he spent with me discussing this history, Neils Ole Kjeldgaard for his long letter describing his memories, Gordon Lark for his perspective on the history through letters and phone calls, and Gunther Stent for sharing his recollections of Ole's early years in the phage group. Arieh Zaritsky made some intriguing observations and I thank him for his help.

\section{References}

Buchanan, R. E. (1918). Life phases in a bacterial culture. Journal of Infectious Diseases 23, 109-125.

COOPER, S. (1991). Bacterial Growth and Division: Biochemistry and Regulation of the Division Cycle of Prokaryotes and Eukaryotes. San Diego: Academic Press.

HENRICI, A. T. (1928). Morphologic variation and rate of growth of bacteria. In Microbiology Monographs. London: Ballière, Tindall \& Cox.

KJeldgaard, N. O., Maaløe, O. \& Schaechter, M. (1958). The transition between different physiological states during balanced growth of Salmonella typhimurium. Journal of General Microbiology 19, 607-616.

Savageau, M. (1991). Reconstructionist molecular biology. New Biology 3, 190-197.

SCHAECHTER, M. (1958). Going After the Growth Curve. In The Molecular Biology of Bacterial Growth. Edited by M. Schaechter, F. C. Neidhardt, J. L. Ingraham \& N. O. Kjeldgaard. Boston: Jones and Bartlett.

Schaechter, M., MaAløe, O. \& KJeldgaArd, N. O. (1958). Dependency on medium and temperature of cell size and chemical composition during balanced growth of Salmonella typhimurium. Journal of General Microbiology 19, 592-606. 